\title{
Comparative Topological Study of Embedded Based Switched Boost Inverter
}

\author{
T. Divya ${ }^{\mathrm{a}, 1}$ and R. Ramaprabha ${ }^{\mathrm{b}}$ \\ a,b Department of EEE, SSN College of Engineering, Kalavakkam-603110, TN, India
}

\begin{abstract}
Extensive study over Z-source inverter (ZSI) has been pursued for years to compensate the drawbacks of the conventional converters. Single stage (one-step) conversion with buck-boost characteristics was the primary features for its wide usage. But presence of passive elements may prove to be a disadvantage as the size of the converter increases along with its ratings. Modifications on such converters leading to different topologies have been discussed briefly in this paper. The comparative study based on reduced passive elements and better gain is done to obtain an optimal converter structure.
\end{abstract}

Keywords: Photovoltaic, Inverters, shoot-through.

\section{Introduction}

The conventional types mainly the voltage source inverters (VSI) and the current source inverters (CSI) were commonly used in applications using renewable sources. But VSI and CSI act only as a buck inverter and boost inverter respectively, i.e. they give only one level of output voltage. As a result they cannot be operated in buckboost state. Adding to it, short circuit and open circuit conditions have a bad influence on the sources and the load of the converter. The ZSI, as shown in Figure 1, have been studied and implemented in literature [1] as a substitute for the conventional types especially in field of photovoltaic (PV), providing a one-step conversion along with its buck-boost characteristics. It has an X-shape structure composing of passive components, providing an impedance source (Z-Source). This constitutes a two-port network with Z-source coupling the dc-input and the inverter circuit. Apart from the buck-boost operation the inverter need no time delay between the turn-on of the switches.

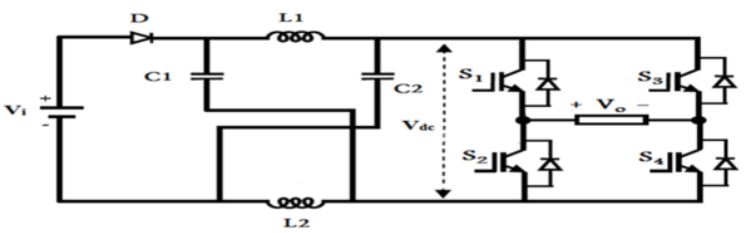

Figure 1. A simplified Source Inverter (ZSI)

\footnotetext{
${ }^{1}$ Divya T ,SSN College of Engineering, Kalavakkam, Chennai, India
}

Email: divyaakkash@gmail.com 
Comparing ZSI with other conventional inverter (c-I), it uses the shoot-through (ST) to increase the gain. The ST improves the boosting number of the overall circuit, improving its reliability and widens its field of application. Similar comparison yields the followings: a) reduced THD \& inrush current, b) high gain with improved switching scheme, and also c) providing an impressive single stage conversion inverter by reducing the cumulative size of the circuit due to a smaller components and their by their effective cost. The ZS technique can be implemented with many applications based on their power conversion stages.

Considering the values of inductors (L) and capacitors (C) are symmetrical for the topologies considered here [1], For ZSI, the capacitor voltage $\left(\mathrm{V}_{\mathrm{c}}\right)$ is

$$
\mathrm{V}_{\mathrm{dc}}=\mathrm{V}_{\mathrm{c}}=\frac{(\mathrm{B}+1)}{2} \mathrm{~V}_{\mathrm{i}}
$$

Where

$\mathrm{B}-\frac{\mathrm{T}}{\left(\mathrm{T}_{1}-\mathrm{T}_{0}\right)}-$ Gain

$\mathrm{T}-$ Total time period

$\mathrm{T}_{1}-$ non-zero time period (active)

$\mathrm{T}_{0}-$ zero time period (ST)

The control of a common ZSI can be done in $n$ number of ways, few of which are discussed in literature [2-3]. Adding to this, a simple three-level (3L) or multi-level configurations can be achieved from voltage and current fed ZSI. The 3L voltagesourced ZSI (Figure 1) raises the following drawbacks: power flow only in one direction, load rating is limited, high inrush current during starting, input current becomes discontinues, higher capacitor voltage in the network, isolating the source and inverter dc rail leading to decreased converter efficiency. There have been many modifications in the structure that have been proposed as an improvisation of basic ZSI topology.

\section{Topological evolutions}

Many topological changes from the conventional ZSI (ZSI) have been derived in literature and in working to expand the merits of the ZSI which are also applicable logically to other buck-boost converters. The primary purpose of topological changes is to compensate the existing drawbacks and thereby furthermore raise their gains, especially for renewable sources of lower voltage for grid connections. The other factor is to raise the modulation ratio $\mathrm{M}$, linking to its primary purpose. Different topological changes that base its derivation around ST have been proposed, some of which as discussed below.

\subsection{Quasi-z-source inverters (qZSI) Heading}

A quasi network (Figure 2) incorporated in the z-source inverter is one of the first modification of the ZSI, which eliminate the drawbacks of ZS network i.e. it provides continuous input current path with L connected in series with source as well as reduces the switching stress and cost. qZSI was obtained from several improvisations to the traditional ZSIs to overcome its disadvantages [4] and has now become a base for separate topological derivations. Another type of qZSI was also presented to 
reduce the voltage stress of the capacitor by adjusting the capacitor cathode position. The qZSI, (Figure 3) on comparison with the ZSI exhibits low voltage stress and continuous input current across $\mathrm{C}_{2}$. In addition, due to presence of $\mathrm{L}_{1}$ the qZSI does not require input capacitance, unlike the ZSI.

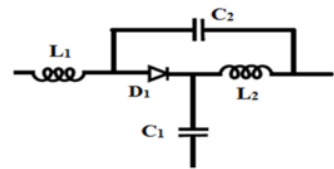

Figure 2. Quasi Network

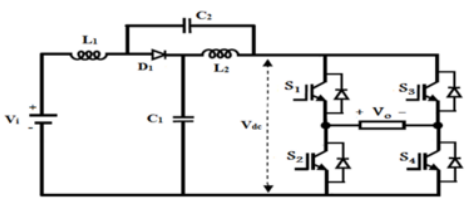

Figure 3. qZSI

The operation of the qZSI can simply be categorized into following modes, regardless of the control strategies may be used: a) the active mode (normal inverter operation); b) the ST mode, occurs when switches of the same leg regardless of the phase conduct and c) When small value of $L_{1}$ and $L_{2}$ causes the discontinuous mode (For analysis part, it was assumed to be large to avoid the discontinuous modes.). The expressions governing $\mathrm{V}_{\mathrm{dc}}$ and $\mathrm{V}_{\mathrm{c} 1}$ and $\mathrm{V}_{\mathrm{c} 2}$ are given as in Eq. (2).

$$
\mathrm{V}_{\mathrm{cl}}=\frac{\left(1-\mathrm{D}_{\mathrm{s}}\right)}{\left(1-2 \mathrm{D}_{\mathrm{s}}\right)} \mathrm{V}_{\mathrm{i}}, \mathrm{V}_{\mathrm{c} 2}=\frac{\mathrm{D}_{\mathrm{s}}}{\left(1-2 \mathrm{D}_{\mathrm{s}}\right)} \mathrm{V}_{\mathrm{i}} ; \mathrm{V}_{\mathrm{dc}}=\frac{1}{\left(1-2 \mathrm{D}_{\mathrm{s}}\right)} \mathrm{V}_{\mathrm{i}}
$$

Wide research on qZSI was carried out to increase the voltage gain which yielded subdivisions of qZSI namely Diode Assisted (DqZSI) and Capacitor Assisted (CqZSI) presented in [5-6]. The problems of high $\mathrm{V}_{\mathrm{c}}$ stress and the discontinuous current from the source were overcome.

\subsection{Embedded $z$-source inverter (e-ZSI)}

Power circuit of the e-ZSI (in Figure 4) presented in [7] also known as inductive series embedded ZSI (ISE-ZSI), as name indicates the source is series connected within the ZS network. This topology also provides uninterrupted source current and reduces the stress across the capacitor. The provision of using multiple sources also expands its application range.

The working of e-ZSI is alike ZSI, where the excitation signals of switches $\mathrm{S}_{1}$ and $\mathrm{S}_{4}$ have phase shift of $180^{\circ}$ with switches $S_{2}$ and $S_{3}$ which causes two ST states, one at the starting and other in the middle of $\mathrm{T}$ period. The reduced capacitor stress attributes to the voltage sharing between the source and capacitor.

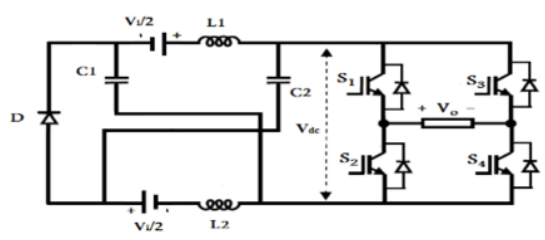

Figure 4. Embedded Switched ZSI

There are 3 operating modes, in which mode 1 operates in shoot through where $V_{c}$ is reduced. In modes 2 or 3 , the stored energy of $\mathrm{V}_{\mathrm{c}}$ is increased. The overall equation for the capacitor voltage is given by 


$$
\mathrm{V}_{\mathrm{c}}=\frac{\mathrm{V}_{\mathrm{i}}}{2\left(1-2 \mathrm{D}_{\mathrm{s}}\right)} ; \mathrm{V}_{\mathrm{dc}}=2 \mathrm{~V}_{\mathrm{c}}
$$

From equation (3) numerator $\left(0.5 \mathrm{~V}_{\mathrm{i}}\right)$ and denominator (1 to 0.5 for varying value of $\mathrm{D}_{\mathrm{s}}$ ), we can conceptually verify the low capacitor stress. Since the topology provides continuous input current the requirement of an LC circuit on the output is highly reduced, there reducing the size of the overall system. The main drawback is the unsustainability of the current leading to asymmetrical operation in the system.

\subsection{Series z-source inverter (s-ZSI)}

Another topology derived to reduce the stress experienced in ZSI is series ZSI (s-ZSI) [8]. It uses another LC network to couple the source with the power circuit. B the varying the Ds the desired $A C$ output voltage is obtained. Apart from the $V_{c}$ stress it also reduces the inrush current value,

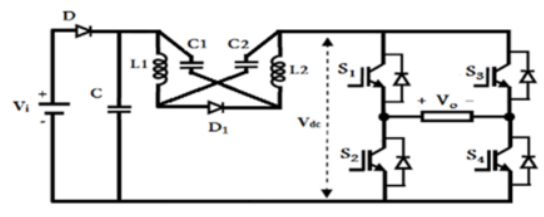

Figure 5. sZSI

Like most of the topologies derived from ZSI, the s-ZSI has 2 primary mode of conduction: during normal cycle (non-ST/Active states), the inverter is simplified as a current source and during the ST cycle, the capacitor voltage charges the inductors, the value are being

$$
\mathrm{V}_{\mathrm{c}}=\frac{\mathrm{D}_{\mathrm{s}}}{\left(1-2 \mathrm{D}_{\mathrm{s}}\right)} \mathrm{V}_{\mathrm{i}} ; \mathrm{V}_{\mathrm{dc}}=\mathrm{V}_{\mathrm{i}}+2 \mathrm{~V}_{\mathrm{c}}=\frac{1}{(1-2 \mathrm{Ds})} \mathrm{V}_{\mathrm{i}}
$$

By changing the value of $D_{S}$, the boost factor can be increased or decreased for example when the PV produces enough input range, the ST is not needed, hence $\mathrm{D}_{\mathrm{S}}=$ 0 which gives $\mathrm{V}_{\mathrm{C}}=0$. The control strategies based on applications and the design of sZSI has been explored in literature [9-10]. The main drawback is its gain which is the same as ZSI.

\subsection{Switched boost inverter (SBI)}

Another novel power converter having the same functionality as ZSI was proposed, switched boost inverter (SBI) [11]. A network of switch $(\mathrm{S})$, diodes $\left(\mathrm{D}_{\mathrm{a}}\right.$ and $\left.\mathrm{D}_{\mathrm{b}}\right)$, capacitor (C) and an inductor (L) connecting the load and the source form the boosting circuit. The main motivation for this topology is to improve the usage of active components than the passive components to improve the losses while retaining the functionality. 


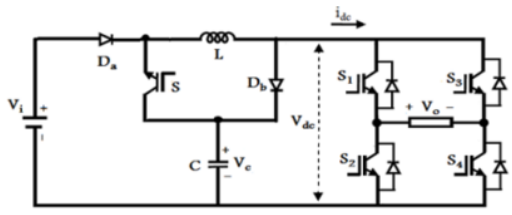

Figure 6. SBI

For the ST operation, the switch $\mathrm{S}$ is on thereby $\mathrm{D}_{\mathrm{a}}$ and $\mathrm{D}_{\mathrm{b}}$ are reverse biased $\left(\right.$ as $\mathrm{V}_{\mathrm{C}}>$ $\mathrm{V}_{\mathrm{i}}$ ), and the $\mathrm{C}$ charges the inductor through switch $\mathrm{S}$ while the inverter bridge is shortcircuited (SC). And for the non-ST mode (Positive and negative cycle), $\mathrm{S}$ is turned off and the inverter is behaves as a current source charging the capacitor. The output equation is given as,

$$
\mathrm{V}_{\mathrm{dc}}=\mathrm{V}_{\mathrm{c}}=\frac{\left(1-\mathrm{D}_{\mathrm{s}}\right)}{\left(1-2 \mathrm{D}_{\mathrm{s}}\right)} \mathrm{V}_{\mathrm{i}}
$$

Despite using more active and less passive components compared to ZSI, the boost factor of SBI is still low for real time PV applications. Adding to it, the topology inserts discontinues current into the circuit and has to be operated at a higher $\mathrm{M}$ (modulation ratio). Many other arrangements of SBI are discussed in literature [12-13]

\subsection{Embedded-switched z-source inverter (ES-ZSI)}

Embedded-switched z-source inverter (ES-ZSI) is the other name for Embeddedswitched boost inverter (e-SBI) [14]. The topology is obtained by adding the features of both e-ZSI and SBI together. The source is included within the switched boost network in series to the inductance, resulting capacitor voltage reduced in halved.

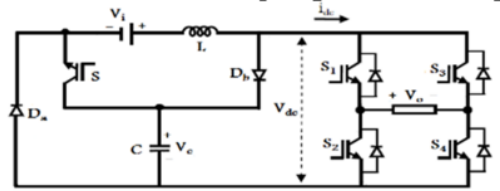

Figure 7. ES-ZSI

There are 3 working modes for this topology similar to that of SBI. For the ST mode, the $\mathrm{S}$ is turned on while the inverter is $\mathrm{SC}$; the $\mathrm{L}$ is recharged in this mode. For the non-ST mode, the inductor feeds the load and recharges the capacitor shown in Eq. (6),

$$
\mathrm{V}_{\mathrm{dc}}=\mathrm{V}_{\mathrm{c}}=\frac{1}{\left(1-2 \mathrm{D}_{\mathrm{s}}\right)} \mathrm{V}_{\mathrm{i}}
$$

And the slope of the inductor current is given by $\left(\mathrm{V}_{\mathrm{C}} \pm \mathrm{V}_{\mathrm{i}}\right) / 2 \mathrm{~L}$, the topology also supplies uninterrupted input current to the circuit, reduces the stress across capacitors. Yet the boost factor though higher than SBI is still low compared to other topologies, hence more modification on the topology is needed to increase the same. 


\subsection{Switched quasi z-source inverter with continuous input current (S-qZSI)}

Recently, a modified switched quasi z-source inverter [15] was stated, to provide both continuous current on the input side and also increase the conversion ratio. It is obtained by replacing a diode from Diode assisted SBI (DA-SBI) with a capacitor (Figure 8.). Though there is no significant change in the capacitor voltage stress, the stress across the switches is greatly reduced.

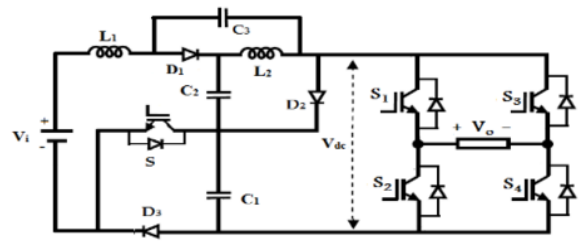

Figure 8. S-qZSI

The operation is much alike prior ZSI, consisting of ST and non-ST modes of conduction. The extra-switch S is on during ST and off during non-ST, more detailed modeling equations during both modes are given [15].

$$
\mathrm{V}_{\mathrm{dc}}=\mathrm{V}_{\mathrm{c} 1}=\frac{1}{(1-3 \mathrm{Ds})} \mathrm{V}_{\mathrm{i}} ; \mathrm{V}_{\mathrm{c} 2}=\mathrm{V}_{\mathrm{c} 3}=\frac{\mathrm{D}}{\left(1-3 \mathrm{D}_{\mathrm{s}}\right)} \mathrm{V}_{\mathrm{i}}
$$

Compared with SBI and DA-SBI, the boost factor of the proposed S-qZSI is improved and the dc source current is also found to be continuous. Moreover, the voltage stresses of the power switches are lower than the SBI, DA-SBI, yet the stress across capacitor remains the same.

\section{Topological Comparison}

Many more topologies can be studied from the literature that fulfils one or many requirements of a PV or related applications [16-17]. Designing a converter that can surmount all the shortcomings of common topologies is impractical in our present or near future. The topologies also show that changes in existing topologies can improve the performance of the overall systems. Keeping that in mind a tabulation of the above topologies based on the following parameters are presented in Table 1.

The gain and the capacitor voltage values: the main parameter that decides the viability of the topology is the gain and the voltage stress. The stress across the capacitor is needed to calculate the overall loss of the system.

Passive and the active components: These components are required for the calculation of size of the overall system thereby determining the practicality. The other factor that contributes majorly to the loss calculation is the loss in the passive elements. From the table below, it's inferred that all the topologies are a variation in each other to improve the performance of the overall system. While most of them have the same gain level, the problems of inrush current, voltage stress, filter components were compensated. SBI produces higher gain value than the rest but the discontinuous input current limits its applications. 
Table 1. Topological analysis of inverters

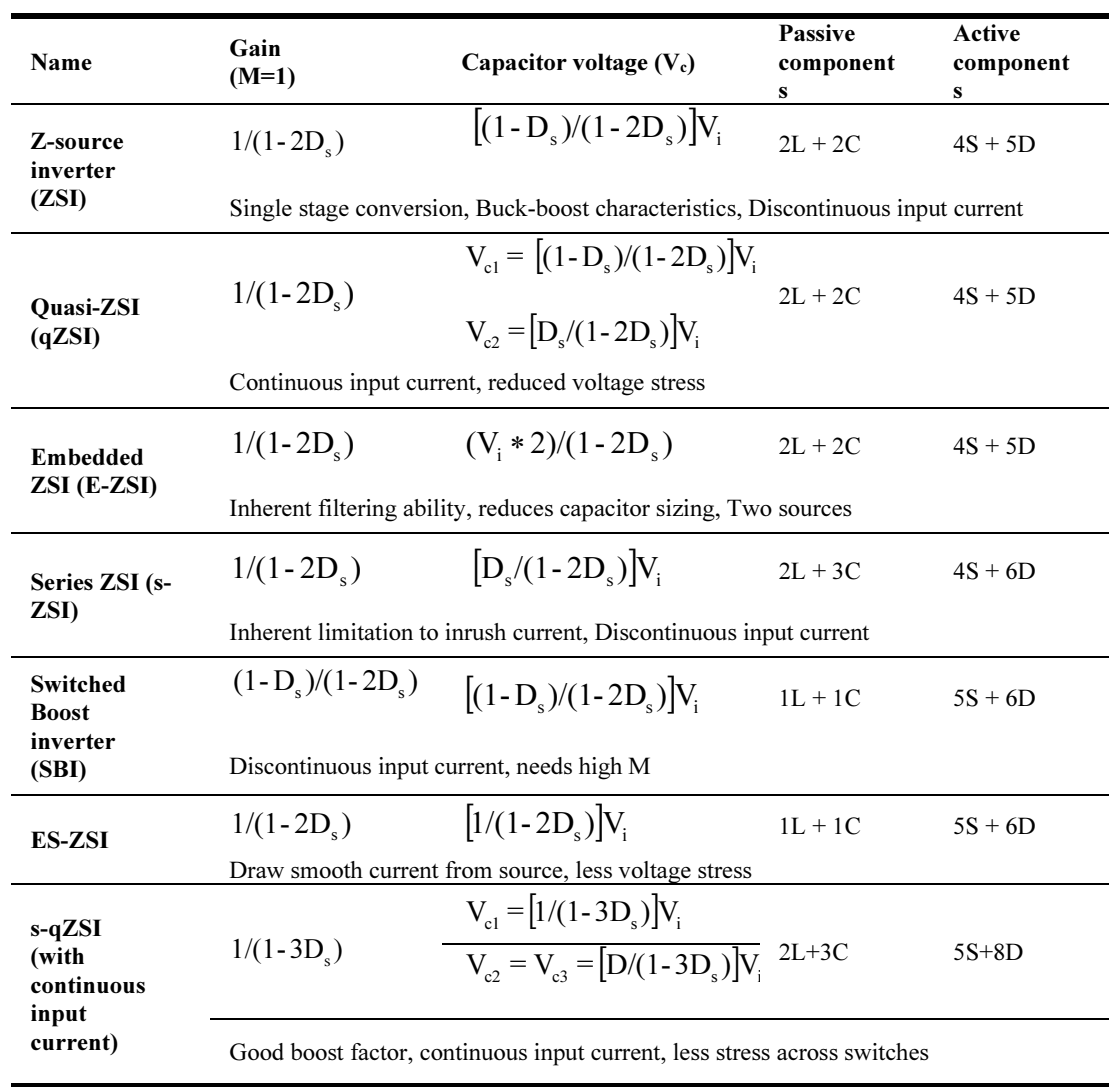

Meanwhile, the S-qZSI has improved gain and provides smooth current to the circuit the increased number of passive components increase the overall size and loss of the system. To achieve a balance between the features, ES-ZSI is considered a preferable topology for a PV connected system providing continuous current and reduced passive components.

\section{Conclusion}

The ZSI is the heart of modern power conversion topology. This power electronics topology was presented to overcome the traditional VSI and CSI limitations. It buckboost characteristics and also one-step conversion makes it an efficient topology in almost all applications. It uses the ST (short-circuit) in the most effective way to boost the output voltage, improving its reliability and widens its application fields. Yet it poses few drawbacks to the overall systems due to which many topological changes have been implemented in literatures. As such the comparison of all the topologies is a tedious process as the merits and demerits differ for each based on their structural functions. This paper presents a few specific topological improvements of Z-source network to compensate those shortcomings and its comparative study based on central parameters is presented briefly. 
For further study and analysis, the ES-ZSI is chosen as optimum topology even with a low gain factor. This result may vary based on the applications and other specification of the converter. But the gain of the topology can be increased by replacing $\mathrm{L}$ with a switched-inductor (SL)/switched-capacitor (SC). This might increase the passive components but the overall loses is still lower when compared with other topologies. This overview aims to help researchers to understand and present a thought on identifying the most suitable converter based on their specifications.

\section{References}

[1] Fang Zheng Peng. Z-source inverter. IEEE Industry Applications Conference - 37 $7^{\text {th }}$ Annu. Meeting; 2002 Oct 13-18; Pittsburgh, PA, USA: IEEE; c2002. 775 p.

[2] Budi Yanto Husodo, Shahrin Md. Ayob, Makbul Anwari, Taufik. Simulation of Modified Simple Boost Control for Z-Source Inverter. International Journal of Automation and Power Engineering (IJAPE). 2013 May; 2(4): 57-64.

[3] K. Vibha, K. Sudha. Design of Chopper Fed Z-Source PWM Inverter. International Journal of Pure and Applied Mathematics. 2018; 119(12): 15165-15175.

[4] D. Vinnikov, I. Roasto, R. St rzelecki, and M. Adamowicz: Step-Up DC/DC Converters with Cascaded Quasi-Z-Source Network. IEEE Trans. Ind. Electron. 2012 Oct; 59(10) 3727-3736.

[5] Chandana Jayampathi Gajanayake ; Fang Lin Luo ; Hoay Beng Gooi ; Ping Lam So ; Lip Kian Siow: Extended-boost Z-source inverters. IEEE Trans. Power Electron; 2009 Sep 20-24; San Jose, CA, USA: IEEE; c2010. 2642 p.

[6] Chandana Jayampathi Gajanayake, Fang Lin Luo, Hoay Beng Gooi, Ping Lam So. Lip Kian Siow, Q. N. Vo. Simple modulation and control method for new extended boost quasi Z-source. In: Proc. TENCON; 2009 Jan 23-26; Singapore, Singapore: IEEE; c2010. p. 1-6.

[7] F. Gao, P.C. Loh, D. Li, and F. Blaabjerg: Asymmetrical and symmetrical embedded Z-source inverters. IET Power Electronics. 2011 Feb; 4(2): 181-193.

[8] Yu Tang, Shaojun Xie, Chaohua Zhang, Zegang Xu. An improved Z-source inverter. IEEE Trans. Power Electron. 2011 Dec; 26(12): 3865-3868.

[9] Yu Tang, Shaojun Xie. System design of series Z-source inverter with feed forward and space vector pulse-width modulation control strategy. IET Power Electron. 2014 Mar; 7(3): 736-744.

[10] J. Kitson, D. Drury, P.H. Mellor. Evaluation of measured signals and control scheme design for a series Z-source inverter. 7th IET International Conference on Power Electronics, Machines and Drives (PEMD); 2014 Apr 8-10; Manchester, UK: IET; c2014. p. 1-6.

[11] AddaRavindranath, Santanu K. Mishra, and Avinash Joshi: Analysis and PWM control of Switched Boost Inverter. IEEE Trans. Industrial Electronics. 2013 Dec; 60(12): 5593-5602.

[12] Anh-Vu Ho, Tae-Won Chun, Heung-Geun Kim: Extended boost active-switched capacitor/switchedinductor quasi-Z-source inverters. IEEE Trans. Power Electron. 2015 Oct; 30(10): 5681-5690.

[13] M. Hasan Babayi Nozadian, E. Babaei, S. H. Hosseini, E. Shokati Asl: Steady-state analysis and design considerations of high voltage gain switched Z-source inverter with continuous input current. IEEE Trans. Ind. Electron. 2017 Jul; 64(7): 5342-5350.

[14]EbrahimBabaei, Elias ShokatiAsl, Mohsen HasanBabayi, and Sara Laali: Developed Embedded Switched-Z-Source Inverter. IET Power Electronics. 2016 Jul; 9(9): 1828-1841.

[15] JingYuan, YonghengYang, FredeBlaabjerg: A Switched Quasi-Z-Source Inverter with Continous Inout Currents. 10th International Conference on Power Electronics and ECCE Asia (ICPE 2019 - ECCE Asia); 2019 May 27-30; Busan, South Korea: IEEE; c2019. p. 1-6.

[16] Tao Li, Qiming Cheng. A comparative study of Z-source inverter and enhanced topologies. CES Transactions on Electrical Machines and Systems. 2018 Sep; 2(3): 284-288. 